Pedagogía y Saberes n. ${ }^{\circ} 53$ Universidad Pedagógica Nacional

Facultad de Educación. 2020. pp. 121-132

\title{
La infancia y la escuela en las voces de excombatientes*
}

\section{Artículo de investigación}

Childhood and School in the Voices of Ex-combatants

Infância e escola na voz de ex-combatentes

\author{
Elizabeth Torres Puentes**
}

\section{Para citar este artículo:}

Torres, E. (2020). La infancia y la escuela en las voces de excombatientes. Pedagogía y Saberes, 53, 121-132. https://doi. org/10.17227/pys.num53-10502

* El presente artículo presenta parte de los resultados finales de la tesis doctoral titulada "Temporalidades en narrativas de excombatientes: experiencia humana de infancia y educación", en el marco del Doctorado Interinstitucional en Educación de la Universidad Distrital.

** Doctora en Educación, Universidad Distrital, Bogotá, Colombia. Profesora de Planta Universidad Pedagógica Nacional, Bogotá, Colombia. Miembro del grupo de Educación y Cultura Política.

Correo: etorresp@pedagogica.edu.co.

Código Orcid: orcid.org/0000-0002-3642-0571 


\title{
Resumen
}

El presente artículo de investigación da cuenta de los resultados de la tesis doctoral titulada "Temporalidades en narrativas de excombatientes: experiencia humana de infancia y educación", en el marco del Doctorado Interinstitucional en Educación (Colombia), particularmente, en relación con la interpretación de narrativas de excombatientes que se vincularon a grupos armados en su niñez, sus juicios acerca de la escuela antes, durante y después de su militancia. Los postulados teóricos de Ricoeur $(1995,1999,2005)$ sobre la relación entre temporalidad y narratividad, se tuvieron en cuenta para el análisis de las narrativas de tres excombatientes de las FARC, ELN y AUC, respectivamente. Dicho estudio se realizó bajo la propuesta de investigación narrativa hermenéutica (PINH) desarrollada por Quintero (2018). Los resultados de la investigación dan cuenta de los juicios morales y políticos que emergen en las narrativas de estos excombatientes, y que vinculan la subjetividad que se configura a partir de la experiencia de formación y de infancia.

\section{Palabras clave}

juicio moral; juicio político; infancias; excombatientes

\begin{abstract}
This research article gives an account of the results of the doctoral thesis entitled: "Temporalities in narratives of ex-combatants: human experience of childhood and education", within the framework of the Inter-Institutional Doctorate in Education (Colombia), particularly in relation to the interpretation in narratives of ex-combatants who joined armed groups in their childhood, their judgments about the school before, during, and after their militancy. The theoretical postulates proposed by Ricoeur $(1995,1999,2005)$, on the relationship between temporality and narrativity were taken into account for the analysis of the narratives of three ex-combatants of the FARC, ELN and AUC, respectively. This analysis was developedunder the Hermeneutic Narrative Research Proposal-PINH -, developed by Quintero (2018). The results of the investigation account for the moral and political judgments that emerge in the narratives of these ex-combatants, that link the subjectivity that is shaped from the training and childhood experience.
\end{abstract}

\section{Keywords}

moral judgment; political trials; childhoods; ex-combatants

\section{Resumo}

Este artigo de pesquisa relata os resultados da tese de doutorado intitulada "Temporalidades nas narrativas de ex-combatentes: experiência humana da infância e educação", no âmbito do Doutorado Interinstitucional em Educação (Colômbia), particularmente em relação à interpretação de narrativas de ex-combatentes que estavam ligados a grupos armados na infância, seus julgamentos sobre a escola antes, durante e depois da militância. Os postulados teóricos de Ricoeur $(1995,1999,2005)$ sobre a relação entre temporalidade e narratividade foram levados em consideração para a análise das narrativas de três ex-combatentes das FARC, ELN e AUC, respectivamente. A referida análise foi realizada sob a Proposta de Pesquisa Narrativa Hermeneutica-PINH-desenvolvida por Quintero (2018). Os resultados da investigação explicam os julgamentos morais e políticos que emergem nas narrativas desses ex-combatentes e que vinculam a subjetividade configurada a partir da experiência de treinamento e de infância.

\section{Palavras-chave}

julgamento moral; julgamento político; infâncias; ex-combatentes 


\section{Introducción}

Una problemática que emerge de la vinculación de menores a los grupos armados consiste en la desaparición del lugar de la infancia, pues a pesar de que biológicamente son niños por su edad y contextura física, dejaron de serlo en el sentido de la imputabilidad jurídica al haber asesinado o torturado, pero, sobre todo, porque tuvieron que asumir la crudeza de la experiencia vivida, una guerra cruenta y sin edad. Un menor de edad entrevistado por Lozano (2015) ilustra esta idea: "La etapa de niños la dejamos ahí, escondida y no la terminamos de desarrollar. Crecimos en cuerpo; el alma de niños la dejamos guardada y ahora la queremos sacar y hacer crecer" (p. 82).

El ser niño vinculado al conflicto armado supone una subjetividad distinta y una forma de asumir la experiencia humana que configura al posterior adulto en un proceso de reincorporación. En la vinculación a la vida civil se reconoce necesaria la escuela, ya sea como requisito para culminar los estudios básicos, como proceso de formación en un oficio, o como continuación de un nivel profesional. Quienes se reincorporan, al retornar a procesos escolares, también retornan a la necesidad de construir vínculos con otros, reconocer nuevas identidades y visualizar proyectos de vida, los cuales son intrínsecos a la experiencia escolar.

\section{Marco teórico}

Para el análisis de la experiencia humana de infancia y educación de excombatientes vinculados a los grupos armados siendo niños, se consideraron en el presente estudio las tesis de Ricoeur (1995; 1996), que muestran una relación estrecha entre temporalidad, experiencia humana y función narrativa, pues en sus relatos se hace presente la inteligibilidad que permite comprender el alcance y las consecuencias del conflicto armado, así como repensar un proyecto de escuela y de proceso educativo que acoja a quienes retornan a ella, en el marco de un proceso de reincorporación.

Ricoeur (1999) señala que en los campos del conocimiento de la filosofía, la epistemología de la historia y la crítica literaria, no se encuentra relación íntima entre función narrativa y experiencia del tiempo. Una posible explicación es que su estudio se ha restringido a la cosmología y la física, o a que su análisis se ha ceñido a la comprensión de la subjetividad, pero sin vincularlo con la experiencia humana intersubjetiva, por ello se ha llegado a considerar que el tiempo y la experiencia humana son dos temas ajenos el uno al otro.
Para el mismo autor (1999), la importancia de comprender el vínculo estrecho entre función narrativa y experiencia del tiempo consiste en:

- Mostrar cómo los usos del lenguaje no se reducen a sus sentidos lógicos o a su organización sintáctica pues, el lenguaje posee una amplitud y una diversidad que no es posible de ser simplificada.

- Reunir las formas y modalidades dispersas del juego de narrar presentes a lo largo de las culturas, de las cuales somos herederos y que han sido objeto de diversa ramificación en géneros literarios cada vez más específicos. En este caso se está refiriendo a ampliar los relatos como la epopeya, el drama, el cuento y la novela hacia otros modos distintos del lenguaje como el cine, la pintura y las artes plásticas.

- Poner a prueba nuestra capacidad de selección y organización del lenguaje. En otras palabras, cuando el lenguaje se organiza en unidades de discurso más largas que la frase llamadas textos (p. 190).

A partir del vínculo entre función narrativa y tiempo, el autor procede a exponer lo que entiende por trama narrativa como el resultado de la delimitación de la ordenación y significación de los acontecimientos y de las acciones narradas para configurar una historia completa.

La trama se relaciona con la experiencia humana en la medida en que es el sustrato de la historia que cuenta el hombre: "la experiencia constituye una verdadera demanda del relato" (Ricoeur, 2009, p. 52). En otras palabras, la experiencia compone un relato y el relato se constituye de la experiencia humana. El autor también hace claridad frente a que las historias que se narran se viven imaginariamente, con esto se rompe la falsa idea de que la vida se vive y no se narra.

Por su parte, para la comprensión de los juicios morales y políticos que enunciaron frente a su experiencia, se tuvo en cuenta que estos son los razonamientos por medio de los cuales los sujetos señalan que una situación es buena/mala, correcta/incorrecta, justa/injusta, atendiendo a sus modos de valoración. Un juicio moral posibilita analizar situaciones de convivencia en contextos reales o hipotéticos, considerar pros y contras, evaluar posibles consecuencias de las acciones, asumir un punto de vista basado en razones suficientes y tomar decisiones responsables según una jerarquía de principios y valores humanos que determinan lo que realmente el sujeto es en el mundo (Kohlberg, citado por Pinedo, 2015). 
Para Arendt (citada por Guerra, 2003), un juicio político consiste básicamente en el uso del pensamiento representativo y de la imaginación para ponerse en el lugar del otro, y comprender desde ese lugar las estructuras de poder. El juicio político es concebido como elemento sustancial en una ética de la responsabilidad, comprendida como la posibilidad de dar cuenta de las acciones humanas.

\section{Metodología}

En el marco de la investigación que da origen a este artículo, se entrevistaron 18 excombatientes de los distintos grupos armados que mayoritariamente han hecho presencia en el territorio colombiano. Se adoptó el diseño de investigación narrativa, la cual es concebida como un proceso complejo y reflexivo, de mutación de los textos del campo a los textos para el lector (Bolívar, 2002), por lo que debe atender las siguientes características:

- Representar un conjunto de dimensiones de la experiencia que la investigación formal deja fuera (sentimientos, propósitos, deseos, etcétera).

- Las categorías de análisis surgen de los relatos o testimonios de los sujetos investigados.

- Tiene en cuenta la realidad interna del informante en relación con un contexto externo, lo que permite encontrar significados y sentidos a la realidad vivida en la experiencia relatada.

- Situar las experiencias narradas en el discurso dentro de un conjunto de regularidades y pautas explicables sociohistóricamente, bajo el pensamiento que el relato de vida responde a una realidad socialmente construida; sin embargo, no se puede desdeñar que es completamente única y singular.

De acuerdo con lo anterior, un análisis narrativo reconoce:

[...] estudios basados en casos particulares (acciones y sucesos), pero cuyo análisis (narrativo, en sentido estricto) produce la narración de una trama o argumento, mediante un relato narrativo que torne significativos los datos. Aquí no buscamos elementos comunes, sino elementos singulares que configuran la historia (Bolívar, 2002, p. 13).

En el marco de la investigación de la que da cuenta este artículo, se pretendió configurar los elementos de los relatos de los adultos vinculados a los grupos armados cuando aún eran niños. Estos dieron origen a una historia única y con sentido, en términos de Ricoeur (1999), con el fin de expresar de modo auténtico las estructuras narrativas del tiempo.

En el campo de lo educativo, la investigación narrativa permite que los relatos sean usados para acciones formativas (Jackson, 1995); en este caso, los relatos de estos adultos que afirman que la vinculación se constituyó como un punto de inflexión en su vida y en su experiencia escolar pueden ayudar a comprender el conflicto colombiano y algunas realidades que no son tratadas en la escuela, porque sencillamente no son curricularizables.

Al aproximarse a los relatos de adultos que otrora fueron niños guerrilleros o paramilitares, se da un cambio de perspectiva de quien la relata y la escucha, así lo ilustra Jackson (1995): “[...]se supone que después de haber oído esos relatos seremos mejores, se supone que experimentaremos un cambio no sólo benéfico, sino también duradero" (p. 26). En últimas, estas narrativas van orientadas a formar una memoria histórica de los hechos que lleven a que nunca más se repitan, pues tienen dos funciones:

- Epistemológica. En la experiencia plasmada en los relatos de quienes han sido militantes de los grupos armados desde su niñez, se explicita un saber sobre la guerra, las desigualdades, la historia del conflicto, la historia de las víctimas, etc.

- Transformadora. Al relatar la experiencia de ser niños y adolescentes vinculados a los grupos armados se potencia una fabulación que justifica las acciones, y por tanto dejan una enseñanza que puede transformar. Como lo anota Jackson (1995), estas transformaciones pueden ser tanto positivas como negativas.

Se entiende que las dos funciones propuestas por Jackson, y adoptadas para este estudio, se encuentran en relatos que tienen una estructura única, coherente, con sentido y completa. Para evaluarla se propone seguir lo planteado por Labov (1988), quien entiende la narrativa como "un método de recapitular experiencias pasadas apareando una secuencia de cláusulas ${ }^{1}$ verbales con una secuencia de eventos que (según se infiere) en la realidad ocurrieron" (p. 10).

1 Labov (1988) afirma que la estructura de una narrativa consiste en una serie de cláusulas temporalmente ordenadas llamadas cláusulas narrativas. Las cláusulas están típicamente ordenadas de acuerdo con la secuencia de tiempo, por lo que una narrativa mínima será aquella conformada por una secuencia de dos cláusulas que están organizadas de acuerdo con el tiempo. Una cláusula libre es aquella que no está limitada por ninguna unión temporal. 
Se adoptó la estrategia de sistematización de análisis narrativo propuesta por Quintero (2018). En ella se asumen momentos específicos en los que se realiza un nivel de recolección, organización y sistematización, lo que corresponde a la dinámica propia del círculo hermenéutico. Los momentos propuestos por la autora son:

- Momento 1. Registro de codificación, que corresponde a la transcripción y asignación de códigos de identificación de cada una de las narrativas.

- Momento 2. Nivel textual: preconcepción de la trama narrativa, que permite reconocer sus elementos prefigurativos, como lo son los actores y sus acciones, espacialidades y temporalidades.

- Momento 3. Nivel contextual de la trama narrativa: en el que se identifican los contextos propios de los actores y sus fuerzas narrativas.

- Momento 4. Nivel metatextual: reconfiguración de la trama narrativa, el cual permite volver a leerla a la luz de quien investiga.

Estos cuatro momentos permitieron reconocer los juicios sobre infancia y escuela presentes en las tres narrativas seleccionadas, que corresponden a tres sujetos (dos mujeres y un hombre) que nacieron y crecieron en contextos rurales en Colombia. Su infancia y, en general, su existencia estuvo enmarcada por el conflicto armado, cuyos actores principales fueron las guerrillas (ELN y FARC), los paramilitares (AUC) y el ejército colombiano.

\section{Resultados}

A continuación, se presentan los juicios morales y políticos hallados en las narrativas de los excombatientes seleccionados, en dos categorías:

- Juicios morales y políticos acerca de la escuela. Allí se exponen los juicios antes, durante y después de la vinculación al grupo armado, en relación con su experiencia con lo educativo. El tiempo cronológico del antes, durante y después de uno de los hitos que marcaron la vida de los excombatientes, como lo es haber pertenecido a un grupo armado, es clave para identificar las temporalidades que configuran sus subjetividades.

- Juicios políticos y morales acerca de las infancias configuradas por/en la guerra. Se da cuenta de los juicios presentes en las narrativas de los excombatientes que se vincula- ron siendo niños y que formaron parte de la investigación, relacionados con su infancia; así como las múltiples infancias que configuran las subjetividades de quienes participaron en la guerra y que hoy se encuentran en procesos de reincorporación.

\section{Juicios morales y políticos acerca de la escuela: "¿Cómo iba a cambiar algún día un lápiz por un arma?"}

Un primer juicio político acerca de la escuela antes de la vinculación se relaciona con asumirla como oportunidad de no ser parte de la guerra. Los excombatientes entrevistados reconocen que si la escuela de su experiencia humana, antes de su vinculación al grupo armado, hubiese sido garantizada por el Estado, con reconocimiento de su derecho a educarse y sin tantas violencias en la institución y en el territorio, jamás habrían contemplado la vinculación al grupo armado como una posibilidad y seguramente se hubiesen construido raíces fuertes que los sujetaran a otros proyectos de vida. Tal como lo relata el excombatiente de las autodefensas: “Cómo iba a cambiar algún día un lápiz por un arma? Nunca, nunca llegué a pensar eso, en mi mente nunca estaba eso... en mi mente era estudiar y estudiar" (excombatiente AUC).

Un segundo juicio político, presente en las narrativas de los excombatientes antes de su vinculación al grupo armado, reseña las condiciones de la escuela rural, como muestra de ausencia del Estado. En este sentido, los relatos de los tres entrevistados describen una dificultad en la asequibilidad, definida como deficiencia en el presupuesto, en edificios y en maestros que cubran la demanda, también en infraestructura y dotaciones no pertinentes (Tomasevski, 2004). Las escuelas de estos tres sujetos, antes de vincularse al grupo armado, eran escuelas precarias, gestionadas por un solo profesor a cargo de todos los cursos y todas las áreas, bajo el modelo de escuela nueva, con condiciones laborales y de seguridad frágiles. Lo que hizo que el servicio educativo fuera ofrecido con ciertas intermitencias, en algunos casos muy prolongadas, como lo relata una de las entrevistadas:

[...] No había profesores de tiempo completo, solamente mandaban uno y tenía que dictar lo que era la primaria; en el año dictaba tres meses, se retiraba porque las condiciones del área rural eran totalmente pésimas. Había que ir cuatro horas de a caballo a la escuelita de donde los dejaba a ellos el bus, y pues, lógicamente, para ellos era muy duro (Excombatiente de las FARC). 
Las escuelas antes de la vinculación, que se describen en los relatos, también tienen dificultad en la adaptabilidad, entendida como la pertinencia del currículo y la oferta educativa de acuerdo con contextos y poblaciones específicas (Tomasevski, 2004). Así, los excombatientes, describen una escuela tradicional en la que se mantiene la idea de aprendizajes y currículos hegemónicos cuyo único y principal propósito es enseñar a leer, escribir y realizar las cuatro operaciones matemáticas. Esta idea de escuela tradicional antes de la vinculación no contextualiza los aprendizajes, y, en palabras de una de las entrevistadas, "no enseña a pensar" (excombatiente de las FARC).

También se presentan en la escuela antes de la vinculación dificultades en la accesibilidad, que configura la gratuidad, accesibilidad económica, material y geográfica a las instituciones educativas (Tomasevski, 2004). Las tres narrativas coinciden en que la accesibilidad geográfica a las escuelas era complicada, debían caminar muchas horas para llegar a ella. Sobre este aspecto, solo la narrativa de la excombatiente del ELN es clara en problematizar la gratuidad y accesibilidad económica, pues si bien se trataba de instituciones públicas, la familia en contextos rurales se vio sometida a grandes desplazamientos, lo que muchas veces implicó inversiones en vivienda y manutención para acceder a colegios más grandes en los que se pudiera continuar los estudios de la básica primaria y del bachillerato:

\begin{abstract}
El recuerdo más triste, cuando terminé el año, que me entregaron los documentos, o sea, los papeles, todo, los diplomas y todo, pero ahí, o sea, el profesor le dijo a mi mamá que dónde me iba a poner a estudiar que porque era buena esa alumna y eso, y mi mamá le dijo a él, pues, delante de mí, que estaba pensando porque ella no tenía los recursos necesarios, entonces, para mí... o sea, para mí eso fue triste $¿ s i ́$ ? Porque mi anhelo era seguir estudiando, pero no se podía (Excombatiente ELN).
\end{abstract}

Adicionalmente, los relatos de estos tres excombatientes reconocen que antes de su vinculación la escuela a la que se asistieron presentó vacíos de aceptabilidad, la cual está configurada por la calidad de la educación asociada a las necesidades, intereses y expectativas de las diversas comunidades y poblaciones (Tomasevski, 2004). En los tres relatos, la escuela antes de la vinculación fue considerada por los excombatientes como una forma de movilidad social; sin embargo, por sus narrativas, tal ilusión nunca se materializó, aunque ahora, con miras al futuro, la perfilan en un proyecto de vida estable y realizable. Esto determina en las narrativas de los excombatientes una vida precaria. Para Butler (2009):
[...] la idea de "precaridad" determina aquello que políticamente induce una condición en la que cierta parte de las poblaciones sufren de la carencia de redes de soporte social y económico, quedando marginalmente expuestas al daño, la violencia y la muerte. [...] La precariedad también caracteriza una condición política inducida de vulnerabilidad maximizada, es una exposición que sufren las poblaciones que están arbitrariamente sujetas a la violencia de estado, así como a otras formas de agresión no provocadas por los estados pero contra las cuales estos no ofrecen una protección adecuada (pp. 322-323).

En las narrativas de estos excombatientes, vinculados a los grupos armados siendo niños, se hace presente un tiempo de la precariedad, materializado en juicios morales que se hace sobre la familia, en este caso una familia extensa que presenta dificultades para mantener a sus miembros, pues no tienen soporte social y económico que les permita garantizar condiciones mínimas de vida.

Esta realidad de familia extensa tiene una implicación importante en la vida de la excombatiente de las FARC y el excombatiente de las Auc, quienes tienen la necesidad de vincularse a una vida laboral desde niños, no solo para ayudar a la manutención de la familia, sino también para garantizar su propia subsistencia. La precariedad implicó que estos dos excombatientes fueran víctimas de violencia física en su familia:

[...] Mi papá era muy conflictivo con mi mamá, él entraba siempre en choque, era alcohólico, peleaba mucho, sacaba a veces un machete y a darnos a todos, a volarnos la cabeza (Excombatiente AUc).

[...] Un día mi mamá me cogió a juete ventiado, porque yo no quise ir a lavar el corral de los marranos, ella hablaba y rapidito había que hacer caso. Yo no quería ir a la marranera, porque no me gustaba ese trabajo, prefería ayudar a recoger la cosecha o sembrar pero no lavarle la porquería a los marranos (Excombatiente de las FARC).

Un tercer juicio político sobre la escuela antes de la vinculación consiste en que ella es descrita como un lugar de exclusión y a la vez de aprendizajes básicos. En ese sentido, la excombatiente de las FARC vivió maltrato y violencias en la escuela. Ella, al ser estudiante y a la vez empleada doméstica de una de sus profesoras, no vivía la vida escolar como el resto de sus compañeros; como ella lo indica, sus descansos eran para hacer la comida, lavar y planchar. Sin embargo, pese a la adversidad, reconoce que hubo aprendizajes significativos no curricularizados relacionados con el arte y la culinaria: "Ella me enseñaba 
aparte de las clases, ella me enseñaba a lavar mi ropa, me enseñaba a organizarme, me enseñaba a preparar comidas" (excombatiente de las FARC).

En el caso del excombatiente de las Auc, se presentó exclusión por parte de sus maestros y compañeros por no contar con los elementos necesarios para la actividad escolar; no obstante, su esfuerzo y sacrificio lo llevan a autoevaluarse como un sujeto perseverante: "La enseñanza de los maestros me hacía feliz, porque yo, a pesar, me esforzaba, así llegara con sueño, en hacer mis tareas, en cumplir, yo era muy feliz" (Excombatiente AUC).

Por su parte, la excombatiente del ELN vivió la exclusión del sistema educativo por la imposibilidad de continuar en su municipio con sus estudios. En su narrativa, sin embargo, se presentan expresiones estéticas que la situaban en el espacio público con reconocimiento:

Siempre me gustó lo del modelaje, siempre me gustó. En la escuela jugaba al reinado de belleza y en mi casa yo con mi hermana también jugábamos a eso, bueno, pues, como yo tenía mis accesorios y eso, siempre la pasábamos con ella en eso (Excombatiente ELN).

Los tres entrevistados reconocen que en la escuela aprendieron lo dispuesto en el currículo básico. Esto es, leer, escribir y las cuatro operaciones fundamentales, aunque indican que no lo aprendieron de manera óptima, ya que una de las entrevistadas argumenta que solo cuando estuvo en la guerrilla aprendió a hacer lectura comprensiva y crítica:

[...] Entonces, todo fue muy bonito, porque primero fue la charla política. No entendía de política nada, pero fui corrigiendo lo de escritura, lo de lectura, fui entendiendo la lucha, las raíces del conflicto en Colombia, y todo el tiempo, pues, fue estudio, estudio (Excombatiente FARC).

En las experiencias narradas, los excombatientes coinciden en un juicio moral acerca de la escuela antes de su vinculación, correspondiente a las valoraciones que hacen de los adultos que los rodean. Los tres excombatientes entrevistados esperaban que su familia los apoyara económica y moralmente en la continuación de sus estudios, esperaban que la familia los proveyera. De la misma manera, emiten juicios morales sobre los docentes que acompañaron su proceso escolar. Los excombatientes esperaban que no solo les enseñaran contenidos curriculares que les sirvieran para desenvolverse en su contexto, también que los reconocieran como sujetos que podía aprender, con capacidades diversas, que los cuidaran y que los valoraran:
Porque de igual manera usted puede ser una maestra y yo puedo ser una alumna, pero el alumno a veces puede tener una capacidad, de pronto, bueno, de desarrollar cosas que el maestro también puede aprender de su alumno, entonces me gustaría compartir ideas entre ambos (Excombatiente ELN).

Estas valoraciones morales que los excombatientes hacen sobre la escuela antes de la vinculación refieren a lo que ellos esperaban en el plano del deber ser del adulto, en relación con la infancia desde una concepción de minusvalía, en la que el niño debe ser cuidado, protegido debido a su fragilidad. Esto es, que ellos hoy como adultos esperaban que la escuela los protegiera de su vulnerabilidad propia (para ellos) de ser niños.

Con lo anterior, se reconoce en las narrativas de los excombatientes que formaron parte de este estudio, que la escuela precaria está plagada de acciones violentas y exclusiones. Es coincidente para los tres excombatientes que la escuela, antes de la experiencia del reclutamiento, es un proyecto al que no hubieran renunciado, a pesar de la escasez de sus condiciones que llevó a que se dieran acontecimientos de violencia física, sexual y psicológica. En este sentido, la excombatiente de las FARC vivió en diferentes escuelas, como parte de la no renuncia al sueño de estudiar. La familia prefirió alejarla de su seno y entregarla al cuidado de las profesoras. Sin embargo, ese cuidado y acogimiento no se dio, por el contrario, ella sufrió en la escuela distintas violencias y abusos. Así narra el abuso sufrido por el esposo de una de las profesoras:

Cocinábamos en un fogón, era alto, a mí me tocaba colocar bloques para subirme y una vez estaba encaramada en el fogón tratando de colocar la olla pa' la sopa del almuerzo y el esposo de ella llegó a manosearme, entonces, son cosas de que... [silencio prolongado], y por eso renuncié, cogí mi maleta y me fui, nunca le dije a nadie (Excombatiente FARC).

En relación con los juicios presentes en las narrativas de los excombatientes vinculados siendo niños durante su participación en el grupo, concurren dos juicios de tipo moral. El primero considera al grupo como una escuela donde realmente se aprende para la guerra y para la vida. Con este juicio se concreta la idea de que el grupo armado fue un espacio de protección, aunque paradójicamente sus militantes estaban en constante exposición a la muerte. Esto lleva a preguntar: ¿cómo un espacio de riesgo y expiación se puede concebir como un lugar protector? Además, ¿qué lleva a que muchos niños prefieran los cuidados de un grupo armado y no los de otros entornos sociales cuya razón de ser es la protección? 
Para las dos excombatientes de los grupos guerrilleros, su vinculación les brindó herramientas que la escuela no les dio. En las FARC y el ELN, respectivamente, los aprendizajes van desde hacer lectura comprensiva y crítica de distintos documentos, pasan por el manejo técnico de los sistemas informáticos, e incluyen conocimientos de medicina, todo ello indispensable para la guerra, pero también para la sobrevivencia:

Bueno, y pues el tiempo que yo estuve en la guerrilla yo aprendí mucho, no sabía cómo se manejaba un computador ¿sí ve? Yo hice curso de sistemas, sé manejar una impresora, sé hacer diseños, todo, ¿sí? De medicina sé atender un herido, ¿sí? Normalmente eso nos tocó en la guerra, eso lo aprendí (Excombatiente ELN).

El segundo juicio moral refiere al modelo educativo de la guerrilla que, aunque adopta el esquema de la escuela tradicional, es un modelo que, según las entrevistadas, funciona porque los aprendizajes son significativos y aplicables a la guerra y a la vida misma. En dicho modelo existen roles y dinámicas que provienen del formato de la escuela: un profesor, que en todos los casos detenta un saber superior al de sus discípulos, horarios determinados y acotados para impartir las clases o talleres, enseres habituales como pupitres y tableros. Empero, reconocen que allí el modelo efectivamente funciona, reflexionan que lo que aprendieron allí es de la más alta calidad, pues les permitió ocupar lugares de poder y reconocimiento que seguramente en la escuela tradicional no hubieran logrado, quizás porque el esquema al interior del grupo tiene claro su propósito, que es formar combatientes cualificados política y militarmente para la guerra.

En todo caso, la narrativa del excombatiente de las AUC se distancia de la narrativa de las excombatientes de las guerrillas, pues él afirma que en aquellas no aprendió nada distinto a "mañas y resabios". En su narrativa se puede reconocer que se dieron aprendizajes que favorecieron la adquisición de un perfil laboral, pues dice que en la selva y en la militancia aprendió a trabajar la madera, a construir muebles e implementos necesarios para mejorar las condiciones de entonces.

Con esto, parece ser que a los grupos paramilitares, como al que perteneció este excombatiente, no les interesa formar académicamente a sus militantes, tal vez porque no tienen un proyecto político a largo plazo que propenda por cambiar las estructuras de poder en la que sus huestes puedan aportar (CNMH, 2017). Por el contrario, es posible que estos grupos agoten toda su fuerza en la formación militar y en la formación de una mentalidad en la que solo basta obedecer; en la que no es necesario entender las relaciones de poder, en donde se forma solo en las tareas prácticas de la guerra.
En otro orden de ideas, durante la participación en el grupo armado se hace evidente en las narrativas de estos excombatientes un juicio político sobre los aprendizajes diversos que ofreció el grupo, como la posibilidad de cambiar su realidad precaria, y tener una movilidad social, dentro y fuera de este. A propósito, las excombatientes de los grupos guerrilleros reconocen que el ingreso al grupo armado constituye un punto de inflexión para su formación, y se valoran a sí mismas como afortunadas por lo que aprendieron allí. Reconocen que otra sería su suerte, seguramente como la de la mayoría de mujeres campesinas y pobres, si no se hubiesen reclutado, esto es, mujeres analfabetas, con una familia extensa, dedicadas a la crianza de los hijos y la atención del esposo:

Yo volví a esa vereda hace poco, ¿sí? Ya nadie me distingue, y todas mis amigas, todas las compañeras de clase, todas con hijos, seis, cinco, tres y en una casa, cuidándola, ahí, una casita de mala muerte, se puede decir (Excombatiente ELN).

En este sentido, la selva es considerada un lugar que posibilita diversos saberes. Particularmente, las excombatientes de los grupos guerrilleros asumieron la selva como una escuela, en la que aprendieron a entender el mundo. Ellas, en su condición de militantes de grupos guerrilleros, habitaron cognitivamente la selva, pues en ella no solo recibían clases teóricas de los compañeros que tenían más conocimientos de diversos temas y encarnaban el rol de docentes, sino que también fue un lugar para poner en práctica sus aprendizajes. Por ejemplo, la excombatiente del ELN logró materializar sus conocimientos de enfermería, cada vez que era requerida como médico de primera línea en el combate.

Para las dos entrevistadas, los aprendizajes que les brindaron las guerrillas les permitieron movilidad en el interior al grupo, pues una de ellas se desempeñó como mando y la otra como médico de primera línea, roles fundamentales en la confrontación armada. Además de sobrevivencia en las filas, les brindó movilidad social fuera del grupo, ahora que logran validar su bachillerato sin necesidad de pasar por cada uno de los grados y, según ellas, eso las catapulta a un proyecto de educación superior.

En las narrativas de los tres excombatientes se observó un juicio moral que refiere a la escuela después de su vinculación al grupo siendo niños. Dicho juicio refiere a la escuela como necesaria para cualquier proyecto de vida. Los excombatientes coinciden en afirmar que ahora que se encuentran en un proceso de reincorporación privilegian el proceso educativo ante cualquier otra actividad. Valoran altamente la presencia de la educación en su vida 
después de las armas, porque les ayuda a edificar su proyecto de vida, en el que se encuentra la idea de concretar ese sueño de educación que se les escapó antes de la vinculación.

Además, se hace explícita la autovaloración que cada uno de estos excombatientes manifiesta sobre los conocimientos que individualmente ostentan. Para ellos es válido y relevante lo que aprendieron en el grupo, por ello reclaman que dicho conocimiento debe ser certificado en su actual proceso educativo:

[...] Una vez una psicóloga me dijo: “¿En qué le puedo colaborar? Porque a usted no se le ve nada de que tenga experiencia en nada". Yo le dije: "No, doctora. Yo tengo experiencia en todo: sé plomería, sé de electricidad, sé de pintura, hasta agricultura y usted me dice que no sé nada. Dejemos así". Y yo salí y me fui (Excombatiente AUC).

Aunado a lo anterior, se detectaron dos juicios políticos en las narrativas de estos excombatientes, referentes a la escuela después de la vinculación. El primero alude a la educación y la escuela en relación directa con oportunidades laborales y por ende de mejora de las condiciones de vida. Para los tres excombatientes hay correlación entre educación y empleabilidad, lo que implica la expectativa de un ascenso socioeconómico para ellos y sus familias. Ellos median la decisión de qué estudiar, entre lo que quieren, lo que les hace felices (las artes por ejemplo), y lo que les permitiría obtener un trabajo estable lo más pronto posible, por ello su escogencia se inclina a las carreras tecnológicas: "Sí, bastantes; pero, pues, el tiempo es muy largo y en este momento considero que debemos mirar una [carrera] que se demore menos y que la podamos ejercer más rápido" (excombatiente FARC).

El segundo juicio político detalla el vínculo entre la educación y la escuela para la construcción de un país distinto, más justo y equitativo. Los tres excombatientes valoran la educación como una forma de construcción colectiva de un país en paz. Llama la atención que este juicio supera la filiación política con un grupo determinado; pues, tanto el que fue guerrillero como paramilitar, propende porque la educación le ayude a cambiar las estructuras de poder que actualmente favorecen a unos pocos.

\section{Juicios políticos y morales acerca de las infancias configuradas por/en la guerra: "Puedo decir de que no tuve una niñez"}

En las narrativas de los entrevistados se evidenciaron los juicios morales y políticos que hacen que la niñez y las infancias ${ }^{2}$ queden borradas $^{3}$ por la guerra. Se comparte con Amador-Baquiro (2012) la categoría de infancias, en plural, porque:

[...] reconoce múltiples formas de transitar la niñez [...] se trata de un enunciado que pretende reconocer la urdimbre de experiencias que le dan sentido a la existencia de estos sujetos en relación con sus relaciones con la sociedad, la política, la económica y la cultura (p. 80).

Por ese motivo, en este estudio se reconoce que en las narrativas de los excombatientes que formaron parte de la investigación se hacen presentes múltiples infancias, las cuales se identifican como una construcción social. Para Carli (1999), las infancias se configuran de acuerdo con los rasgos de las sociedades que las enmarcan y a los imaginarios que se tienen de $l a$ infancia. Al admitir que la infancia es una construcción social, esta autora propone que el tiempo de la infancia es posible si hay una prolongación de la vida en los imaginarios de una sociedad; a saber, que la niñez tiene un remanente de existencia más extenso que el de la adultez, también si hay un tipo de vínculo distinto entre el adulto y el niño que devenga en otras formas de educar, ya que: "[...] educar en la sociedad contemporánea requiere en buena medida volver a considerar al niño como sujeto de crecimiento, como un sujeto que se está constituyendo, que vive, juega, sufre y ama en condiciones más complejas, diversas y desiguales" (pp. 17-18).

2 De acuerdo con Amador-Baquiro (2012):

[...]infancias es un término que se distancia de las clasificaciones propias de la psicología evolutiva (niñez, adolescencia, juventud, adultez y vejez). Al situarse en la educación, la pedagogía y los estudios culturales toma como ejes de análisis las dimensiones histórico-culturales y políticas de la sociedad, así como la producción de sentido y de presencia que hacen posible las experiencias de estos sujetos en el mundo de la vida, esto es, acontecimiento, devenir y un constante fluir que se convierte en potencia (p. 81).

3 Se habla de borramiento de la infancia desde la idea que plantea Carli (2009), al expresar que la infancia desaparece por una sujeción de la población infantil a la nación, a la raza o al Estado, mediante políticas represivas, que bien podrían ser entendidas como el abandono del Estado y la continuidad de una vida precaria. 
Así, las narrativas de los tres excombatientes dan cuenta de multiplicidad de infancias: infancia trabajadora, infancia maltratada, infancia violentada, infancia guerrera, infancia insubordinada, infancia escolarizada, infancia desvinculada, etc.

Un juicio moral sobre la categoría de infancias, que se infiere de los relatos recabados en el marco de la investigación, refiere a que una infancia sin juguetes no es infancia. De acuerdo con Cárdenas (2009), los juegos y los juguetes son "actividades y materialidades que guardan estrechas relaciones con las formas en que los infantes, por un lado, han sido interpelados desde los proyectos sociales y políticos y por otro, han experimentado la infancia desde las particularidades de sus contextos" (p. 179). En ese sentido, los tres excombatientes entrevistados en este estudio narran que sus juegos siempre fueron colectivos, nunca jugaron solos. En compañía de hermanos, primos y amigos, jugaron a la lleva, stop, carreras, etc., pero ese tiempo para el juego se veía constantemente interrumpido por la necesidad de ocuparse de la realidad económica: el tiempo para la responsabilidad. Así, se puede considerar un primer borramiento de la infancia al desdibujarse la diferencia entre niño y adulto, desde la idea moderna de las tareas que debe desempeñar cada uno, lo que no implica que la infancia desaparezca (Carli, 2009), pues sigue presente en la imaginación un ingrediente sustancial en el juego que no está.

En la infancia de los tres excombatientes el tiempo para el juego es corto, limitado o inexistente, sin embargo es evidente que para ellos el juego es vital en los imaginarios de infancia, pues aluden que sin este no hay infancia:

Creo que mi niñez fue más niñez de trabajo, que niñez de juego. Puedo decir de que no tuve una niñez... Una lata de sardinas con una cabuya era el carrito, porque no conocía los carros... Mi balón era una bola de trapos (Excombatiente FARC).

Desde otra perspectiva, ese imaginario de infancia también se alimenta de los juguetes que, para la excombatiente de las FARC, eran construidos análogamente con materiales de su contexto (la pelota era de trapos, el carro era una lata de sardinas); para la excombatiente del ELN, podían implicar un rol doméstico (por eso no le gustaba jugar a la cocina); por su parte, para el excombatiente de las AUc eran inexistentes (no tuvo juguetes). Con esto, ellos señalan que la infancia se consolida cuando se juega y se tienen juguetes apropiados para hacerlo, pero también es claro que reconocen que esos juegos y juguetes pueden consolidar perspectivas sobre la vida.
En las narrativas de los excombatientes vinculados a los grupos armados cuando aún eran niños, se evidencian dos tipos de juicios políticos acerca de la infancia. El primero refiere a que una infancia precaria implica una infancia de trabajo, pues no hay otra opción sino trabajar para ayudar a suplir las necesidades del hogar. En consonancia, se da otro tipo de borramiento, que se refleja en un tiempo para el trabajo. A propósito, Carli (2009) afirma que el trabajo infantil es un fenómeno que "indica experiencias de autonomía temprana, una adultización notoria y una ausencia de infancia" (p. 15). Lo que conversa con las narrativas de los excombatientes, particularmente quienes integraron las FARC y las AUC, quienes contaron que no tuvieron infancia porque se vieron obligados a trabajar desde muy niños, asumiendo tareas y responsabilidades propias de adultos.

\section{Entonces yo le ayudé [a mi papá], cuando yo estaba como de doce años, diez, once años me iba con él a las obras... [...] Como en ese tiempo no decían: "Oiga, usted es menor de edad, no entra". No, allá eran obras de puerta abierta, de construcción... y yo llegaba muy rendido, llegaba cansado y ya después el lunes ir a estudiar (Excombatiente AUC).}

Es claro que estos excombatientes tuvieron que asumir un rol de proveedores de su familia, lo que implicó la deserción de la escuela como consecuencia del abandono del Estado como primer garante en la protección de la infancia.

El otro juicio político sobre la categoría infancia refiere a la valoración de una infancia guerrera: "te formarás, te entrenarás, aprenderás a ser guerrero"4. Para el Centro Nacional de Memoria Histórica (2017):

[...] el entrenamiento es una fase en la que se moldea el cuerpo, se instauran las ideas del otro y se afianzan las propias y es el escenario por excelencia de la trayectoria del guerrero en las filas o al servicio del grupo armado (p. 370).

Las narrativas de los tres excombatientes aluden a un tiempo para el entrenamiento mientras formaron parte del grupo siendo niños, y argumentan que era necesario para la formación militar, pues les ayudó a mantenerse con vida en medio de la guerra. Así, con este conjunto de aspectos su infancia se sometió a un borramiento de la idea moderna de infancia, para dar lugar a una infancia entrenada para sobrevivir al enfrentamiento armado.

4 Idea adoptada del Centro Nacional de Memoria Histórica (2017). 


\section{Conclusiones}

Como se ha expuesto en los resultados, los juicios morales y políticos acerca de la escuela, y la infancia de los excombatientes vinculados siendo niños a los distintos grupos armados, que participaron en la investigación de la que emerge este artículo, dan cuenta del impacto del conflicto armado colombiano en los cuerpos y las memorias de quienes por distintas razones formaron parte de una guerra cruenta (Arias, 2014).

Los entrevistados afirman que la escuela como institución no cumplió con su propósito protector, en tanto la excombatiente de las FARC fue abusada sexualmente en una de las escuelas que habitó y sufrió maltratos por sus profesoras-patronas, quienes la veían más como una empleada doméstica que como una estudiante. Por su parte, el excombatiente de las Auc se sintió excluido, discriminado por sus profesores y compañeros, ya que el no tener los elementos escolares lo iba relegando del grupo. A su vez, la excombatiente del ELN se consideró excluida del sistema al no poder continuar sus estudios, porque su vereda no contaba con la infraestructura para permitírselo.

Con lo anterior, según las experiencias narradas, la escuela no protegió a los excombatientes que formaron parte de esta investigación, no los acogió, situación que los llevó a la deserción del sistema escolar y, posteriormente, en conjunto con otras razones, a la vinculación al grupo armado. Sin embargo, por distintas causas, han configurado subjetividades que les permiten leer la realidad de hoy de una manera distinta, realizar planes de vida en los que no renuncian al proyecto de escuela como una oportunidad que los afinca a una vida distinta, una vida de paz, pero sin renunciar a los aprendizajes que otrora les reconocieron como sujetos capaces, valiosos y que les posibilitaron hacerse un lugar en los grupos.

En las narrativas de los tres sujetos, que se tomaron como muestra significativa para la investigación (desde Ricoeur 1999; 1995; 2005, cada narrativa es única, y da cuenta de tramas valiosas para poder indicar que una vida examinada y por tanto digna de ser vivida y narrada), se evidencia que se borra la idea de una única infancia, para dar cabida a múltiples infancias. En el caso de los entrevistados, se dio cuenta de la infancia guerrera, la infancia trabajadora, la infancia maltratada, la infancia precaria; pero también de una infancia con momentos de felicidad, en medio de las condiciones de violencias acaecidas.

\section{Referencias}

Amador-Baquiro, J.C. (2012). Condición infantil contemporánea: hacia una epistemología de las infancias. Pedagogía y Saberes, 37, 73-87. https://doi.org/10.17 227/01212494.37pys73.87

Arias, D. (2014). Memorias de la guerra en Colombia. Relatos de una mujer excombatiente. Eleuthera, 10, 207-224. http://eleuthera.ucaldas.edu.co/downloads/ Eleuthera10_12.pdf

Bolívar, A. (2002). “¿De nobis ipsis silemus?”: Epistemología de la investigación biográfico-narrativa en educación. Revista Electrónica de Investigación Educativa, 4(1), 1-26. http://redie.uabc.uabc.mx/vol4no1/contenido-bolivar.html

Butler, J. (2009). Performatividad, precariedad y políticas sexuales. AIBR. Revista de Antropología Iberoamericana, 4(3), 321-336. https://www.redalyc.org/ pdf/623/62312914003.pdf

Cárdenas, Y. (2009). Memorias de juego y juguetes: otras formas de hacer historia de la infancia. En A. Jiménez y F. Guerra, F. (comps.), Las luchas por la memoria (pp. 157-178). Bogotá: Universidad Distrital Francisco José de Caldas.

Carli, S. (comp.) (1999). La infancia como construcción social. En De la familia a la escuela. Infancia Socialización y subjetividad (pp. 11-39). Buenos Aires: Santillana.

Centro Nacional de Memoria Histórica (CNMH) (2017). Una guerra sin edad. Informe nacional de reclutamiento y utilización de niños, niñas y adolescentes en el conflicto armado colombiano. Bogotá: Autor.

Guerra, M. (2003). Responsabilidad “ampliada” y juicio moral. Isegoría, 29, 35-50. https://doi.org/10.3989/ isegoria.2003.i29.489

Jackson, P. (1995). Sobre el lugar de la narrativa en la enseñanza. En H. McEwan y K. Egan, La narrativa en la enseñanza, el aprendizaje y la investigación (pp. 25-51). Buenos Aires: Amorrourtu.

Labov, W. (1988) Transformación de la experiencia en sintaxis narrativa. Cali: Universidad del Valle.

Lozano, P. (2015). Crecimos en la guerra. Crónicas. Bogotá: Panamericana.

Pinedo, I. (2015). El factor emocional en la construcción del juicio moral: una trayectoria desde Kohlberg al horizonte de la filosofía experimental y la neurociencia cognitiva. Límite. Revista Interdisciplinaria de Filosofía y Psicología, 10(32), 15-25. 
Quintero, M. (2018). Usos de las narrativas, epistemologías y metodologías: Aportes para la investigación. Bogotá: Universidad Distrital Francisco José de Caldas.

Ricoeur, P. (1995) Tiempo y narración I. Configuración del tiempo en el relato histórico. México: Siglo XXI.

Ricoeur, P. (1996). Sí mismo como otro. México: Siglo XXI.

Ricoeur, P. (1999). Historia y narratividad. Barcelona: Paidós.

Ricoeur, P. (2005). Volverse capaz, ser reconocido. Esprit, 7. http://www.di-plomatie.gouv.fr/fr/IMG/pdf/Revue_ des_revues_200_112B78.pdf.
Ricoeur, P. (2009). La vida: Un relato en busca de narrador. En Educación y política, (pp. 45-58). Barcelona: Prometeo Libros.

Tomasevski, K. (2004). Los derechos económicos, sociales y culturales: el derecho a la Educación. Sexto informe anual presentado por la relatora especial sobre el derecho a la educación. Washington D.C.: Naciones Unidas-Comisión de Derechos Humanos. 